\title{
The Interactional Origins of Foreigner Talk: Municipal Employees and Foreign Workers
}

\section{Citation}

SNOW, CATHERINE E., ROOS EEDEN, and PIETER MUYSKEN. 1981. "The Interactional Origins of Foreigner Talk: Municipal Employees and Foreign Workers." International Journal of the Sociology of Language 1981 (28). doi:10.1515/ijsl.1981.28.81.

\section{Permanent link}

http://nrs.harvard.edu/urn-3:HUL.InstRepos:34785393

\section{Terms of Use}

This article was downloaded from Harvard University's DASH repository, and is made available under the terms and conditions applicable to Other Posted Material, as set forth at http:// nrs.harvard.edu/urn-3:HUL.InstRepos:dash.current.terms-of-use\#LAA

\section{Share Your Story}

The Harvard community has made this article openly available.

Please share how this access benefits you. Submit a story.

Accessibility 


\title{
The Interactional Origins of Foreigner Talk: Municipal Employees and Foreign Workers*
}

\author{
CATHERINE E. SNOW, ROOS van EEDEN and PIETER MUYSKEN
}

One of the most striking findings to emerge from the various studies of foreigner talk (FT) is the variability in the FT characteristics observed and in the frequency with which they are reported to occur. In studies of FT based on native speakers' introspections about how they would address foreigners, every sentence produced contains some of the familiar FT characteristics deletions, grammatical simplification, lexical analysis, etc. (Ferguson, 1975; Workgroup on Foreign Workers' Language, 1978). In other studies, in which foreign adults were actually engaged in conversation by native speakers, some researchers have reported considerable use of FT as well as imitation of the foreigners' mistakes (Hatch, Shapira and Gough, 1975; Workgroup on Foreign Workers' Language, 1978), whereas some report no use of FT characteristics (Campbell, Schlue and VanderBrook, 1977) and others report that the speech for foreigners is simplified but find no use of incorrect deletions or mirroring of foreigners' mistakes (Gaskill, Campbell and VanderBrook, 1977). How can these differences among the various findings be explained?

One obvious source of variance is the foreign addressee. It may be that foreigners who are perceived as relatively high status, intelligent or the social equal of the native speaker are not addressed with the more extreme FT characteristics, which are reserved for lower-status foreigners. In addition, the perceived second-language ability of the foreigner may be of crucial importance. Foreigners who seem to understand more or whose second-language production is relatively unaccented may elicit fewer foreigner talk characteristics.

A second possible source of variance is the native speaker. Some personality types may be more prone to producing FT than others. Alternately, native speakers who have had considerable experience with foreigners may

\footnotetext{
* The authors would like to express their appreciation to all the members of the work group who collaborated in collecting and analyzing the data discussed here: Reineke Bok-Bennema, Maaike le Grand, Bert Jansen, Hilda Koopman, Patricia Muysken-Menges and Kees Spijker. The first author's current address is: Harvard Graduate School of Education, Cambridge, Mass., U.S.A.
} 
be more aware of the kinds of linguistic modification which can aid communication, whereas native speakers who have little contact with foreigners literally don't know how to talk FT. It is suggestive that extensive use of FT characteristics, including the most extreme FT characteristics leading to the production of ungrammatical sentences, has been found in studies of native speakers who were close friends of the foreign addressee (Hatch et al., 1975, Katz, 1977) or who were ESL teachers and thus had regular professional contact with foreigners (Hatch et al., 1975, Chaudron, 1978).

A further possibility is that the nature of the conversation engaged in may limit the potential for producing FT. In a study of Dutch FT produced in different situations (Workgroup on Foreign Workers' Language, 1978) we found that brief conversations initiated by the foreigner's asking the native speakers where the post office was contained relatively few FT utterances, whereas longer conversations between municipal employees and foreigners engaged in bureaucratic procedures produced much higher levels of FT. Both the brevity of the post-office conversations and the relatively concrete nature of the topic probably contributed to the absence of FT. The administrative conversations were both much longer and dealt with much more complex and abstract topics.

The influence of such factors as the language skill of the foreign addressee and the nature and length of the conversation on the use of FT suggests that an interactional model for FT production should be considered. Within this model, FT is seen as a product of the native speaker's attempt to adjust his speech so as to optimize the foreigner's comprehension and sense of communicative effectiveness. Bloomfield (1933) was the first to suggest that native speakers imitate foreigners' mistakes in an attempt to make their speech more comprehensible, and Lattey and Müller (1976) have more recently proposed an interaction model to explain FT in speech to German guest workers.

Support for this proposal concerning the origins of FT could come from two sources: a demonstration that FT characteristics are identical to the mistakes made by foreigners, and a demonstration that the degree to which FT is used and the kind of FT used is correlated with the language skill of the foreigner being addressed. An interactional origin for FT could explain the differences, noted above, between the kinds of FT found-in studies of interaction between foreigners and native speakers and in studies of native speakers' intuitions about the nature of FT. In a study of Dutch FT we found, for example, that the canonical word order in FT utterances produced by students asked to imagine how they would address foreigners was SOV, whereas in conversations with foreigners natives speakers tended to over-generalize SVO word order. In Dutch there is an alternation between verb final order, used in subordinate clauses and in main clause tenseless verbs, and verb-second, often SVO, in main clause tensed verbs. Thus, the native speakers appealed to 
one pattern when their intuitions were elicited and produced the other existing pattern in the interactions.

The present study was an attempt to assess the extent to which FT has an interactional origin by analyzing the extent to which FT characteristics are similar to the mistakes made by foreigners, and by determining whether the second language proficiency of the foreigner showed any relationship to the amount or kind of FT used.

\section{Procedure}

\section{Collecting the language samples}

The conversations we have analyzed were collected at two municipal offices in Amsterdam, The Netherlands. These particular offices were selected because they both dealt regularly with foreigners, and both therefore had established procedures for handling non-Dutch-speaking clients. The municipal employees recorded were experienced in talking to foreigners.

Recordings were made at the Population Register and the Central Housing Office. The Population Register has the responsibility of maintaining records of all the inhabitants of the city, including information about their age, sex, birthplace, nationality and current address. The Population Register has a separate window for registering people who have just entered The Netherlands, both foreigners and returning Dutch citizens. The conversations at the Population Register were generally fairly short. We recorded conversations between two employees and eight foreigners (see Table 1). (Many more conversations were in fact held during the $31 \frac{1}{2}$ hours we observed at the Population Register, but many of these were with foreigners who were addressed in English, French, German or Italian by the employees.) The Central Housing Bureau is responsible for administering municipal housing policy. One of its primary duties is to provide certificates of urgency to families in severe need of housing, enabling them to obtain rent-controlled housing. The Housing Bureau maintained a special evening service for foreigners with housing problems, during which we made our recordings.

All the conversations were recorded using a tape recorder in plain view of both the employees and the foreigners, and only after the foreigner had read a short description in his own language of what we were doing and had explicitly given his permission to be recorded. During the conversations, notes were taken about the age, sex and nationality of the foreigner being addressed as well as gestures used. 
Table 1. Characteristics of the conversations analyzed

\begin{tabular}{|c|c|c|c|c|}
\hline & $\begin{array}{l}\text { Dutch } \\
\text { speakers }\end{array}$ & $\begin{array}{l}\text { Number of } \\
\text { conversations }\end{array}$ & $\begin{array}{l}\text { Mean number of } \\
\text { utterances }\end{array}$ & $\begin{array}{l}\text { Percentage } \\
\text { FT }\end{array}$ \\
\hline $\begin{array}{l}\text { Population } \\
\text { register }\end{array}$ & $\begin{array}{l}\mathrm{H} \\
\mathrm{G}\end{array}$ & $\begin{array}{l}5 \\
3\end{array}$ & $\begin{array}{l}189 \\
147\end{array}$ & $\begin{array}{r}20.1 \\
7.3\end{array}$ \\
\hline $\begin{array}{l}\text { Housing } \\
\text { bureau }\end{array}$ & $\begin{array}{l}\text { A } \\
\text { B } \\
\text { C }\end{array}$ & $\begin{array}{r}10 \\
7 \\
3\end{array}$ & $\begin{array}{r}94.2 \\
92.4 \\
141.7\end{array}$ & $\begin{array}{l}7.2 \\
9.7 \\
2.2\end{array}$ \\
\hline
\end{tabular}

Transcription of the language samples

All conversations carried out primarily in Dutch with non-Dutch speakers were completely transcribed. The speech was segmented into utterances, using speaker switch and pausing as the primary indicators. Compound sentences were counted as two utterances. The segmentation was always checked by a second judge, and points of disagreement were resolved in discussion between the two judges.

\section{Results}

\section{Quantity of FT}

A first analysis was carried out to determine whether any FT was used in speech to the foreigners and, if so, how much. Each of the native speakers' utterances was therefore classified as being an FT or a normal utterance. This initial classification was carried out intuitively by three judges working independently. The judges made their decisions by reading through the transcript while listening to the tape. Each utterance produced by the native speaker was judged according to the criterion 'Could this have been said in this way to a native Dutch speaker?' If the answer was no, the utterance was classified as an FT utterance. Prosodic factors such as intonation and emphasis were not taken into consideration in the classification. Cases of conflict among the three judges were resolved by discussion.

The percentage of the native speakers' utterances which were classified as FT ranged from 0 to 37.8 in the different conversations, with a mean of 10.5 (see Table 1). The five different native speakers varied considerably in their tendency to use FT; the mean for the lowest user was 2.2, and for the highest user 20.1 (see Table 1). 
A second analysis was undertaken to determine what characteristics the FT utterances showed, and whether these bore any relation to the mistakes most frequently made by the foreigners. The specific substitutions and deletions which occurred in the FT utterances were determined, on the basis of a list of hypothesized FT characteristics which had been compiled using other studies of FT (see Workgroup on Foreign Workers' Language, 1978, for a more complete discussion of these FT characteristics). The FT characteristics were:

1. Determiner deletion and substitution. Ferguson (1975) found both deletion of articles and substitution of demonstratives for articles in FT.

2. Infinitive verb forms. A commonly mentioned FT characteristic is the avoidance of finite verb forms by the use of infinitives.

3. Auxiliary and copula deletion. Ferguson (1971: 1975) found that FT and other simplified registers often showed deletion of copulas and of auxiliary verbs.

4. Simplified negation. Reduction of the negative system to one negative element has been noted for both German (Meisel, 1977) and English FT (Ferguson, 1975, Hatch et al., 1975).

5. Pronoun deletion and substitution. Subject pronouns are often deleted in FT (Ferguson, 1975; Hatch et al., 1975) or strong forms are substituted for weak ones (Meisel, 1975, Ferguson, 1975).

6. Pronoun suppletion. Provision of the normally deleted subject pronoun in FT imperatives has been reported by Ferguson (1975) and Meisel (1975).

7. Juxtaposition. Complex sentences are avoided in FT by using juxtaposition instead of subordination.

8. Canonical word order. Meisel (1975) reports that SOV word order is used canonically in German FT. Ferguson (1975) and Hatch et al. (1975) found absence of inversion in English FT questions, and preposing of negators and adverbia, resulting in a canonical SVO order for English FT.

9. Lexical changes. Lexical simplification by the use of 'analytic translations' (e.g., 'day after today' instead of 'tomorrow') have been reported, as well as the use of some lexical items that seem to function only as FT markers (e.g., savvy in English FT).

All the FT utterances in the conversations were analyzed for the presence of the nine FT characteristics listed above. The results are given in Table 2. It can be seen that some of these characteristics are present in the majority of the FT utterances, whereas others occur rarely. Simplified negation, pronoun suppletion and juxtaposition could not be scored, since no utterances were produced which would have given the opportunity for these character- 
istics to occur. The very high incidence of possessive pronoun deletion can be attributed to the rather special nature of the conversations carried out, in which questions like 'What is your birthplace?' and 'What year was your mother born?' occurred quite frequently.

Table 2. Presence of FT characteristics in the FT utterances studied (percentages)

\begin{tabular}{llll}
\hline & Housing bureau & Population register & Total \\
\hline possessive pronoun deletion & 64 & 98 & 94 \\
determiner deletion & 63 & 90 & 75 \\
auxiliary deletion & 0 & 43 & 32 \\
copula deletion & 9 & 22 & 18 \\
subject pronoun deletion & 9 & 27 & 14 \\
SOV word order in main clause & 10 & 29 & 15 \\
$\begin{array}{l}\text { SVO word order in subordinate } \\
\text { clause }\end{array}$ & 48 & 33 & 47 \\
incorrect infinitive use & 5 & 9 & 6 \\
Frequency of lexical substitutions & & & 9 \\
\hline
\end{tabular}

\section{Foreigners' mistakes}

An analysis of the Dutch used by the foreigners revealed that their frequent mistakes included determiner deletion, pronoun deletion, substituting the infinitive for the finite verb form and deletion of auxiliaries and copulas. The incidence of these mistakes could only be scored for 15 of the foreigners, since the others' utterances were almost all so short that it was impossible to determine precisely what was being deleted or substituted. The 15 foreigners scored varied greatly in the extent to which they made the various mistakes; one made none of these mistakes at all, whereas another deleted $50 \%$ of his auxiliaries and $83 \%$ of his articles. In general, determiner deletion was the mistake made most frequently (mean $=45 \%$ ), incorrect infinitive use was the least frequent (mean $=22 \%$ ), with subject-pronoun deletion and copula and auxiliary deletion of intermediate frequency (means of $39 \%$ and $37 \%$, respectively).

Spearman rho correlations among the various types of mistakes reveal generally positive relationships (see Table 3 ). The foreigners who showed frequent determiner deletion also deleted auxiliaries and copulas frequently, and tended to use infinitives instead of finite verb forms. Subject pronoun 
deletion correlated much less highly with production of the other mistakes.

The results of the analysis of the foreigners' mistakes suggest, then, not only that the major FT characteristics are qualitatively very similar to the mistakes made frequently by the foreigners but also that their order of frequency of occurrence matches their frequency of use in FT utterances. Both the foreigners and the native speakers were most likely to delete determiners, somewhat less likely to delete subject pronouns and auxiliaries and copulas and least likely to use infinitives instead of finite verb forms. This finding does not in itself, of course, prove that FT is the product of imitation of foreigners by the native speakers. It may instead mean that the speech of both the foreigners and the native speakers is subject to processes of simplification which result in these deletions and modifications.

Table 3. Correlations among the frequencies of the four major error types in the foreigners' speech

\begin{tabular}{|c|c|c|c|c|}
\hline & $\begin{array}{l}\text { Deletion of } \\
\text { subject pronouns }\end{array}$ & $\begin{array}{l}\text { Infinitive } \\
\text { use }\end{array}$ & $\begin{array}{l}\text { Deletion of } \\
\text { copulas/ } \\
\text { auxiliaries }\end{array}$ & $\begin{array}{l}\text { Determiner } \\
\text { deletion }\end{array}$ \\
\hline Deletion of subject pronouns & 1.0 & & & \\
\hline Infinitive use & 0.22 & 1.0 & & \\
\hline $\begin{array}{l}\text { Deletion of copula and } \\
\text { auxiliaries }\end{array}$ & $0.35^{*}$ & $0.61 * *$ & 1.0 & \\
\hline $\begin{array}{l}\text { Determiner deletion } \\
*_{\mathrm{p}}<0.10\end{array}$ & $0.35^{*}$ & $0.75^{* *}$ & $0.62 * *$ & 1.0 \\
\hline$* * \mathrm{p}<0.01$ & & & & \\
\hline
\end{tabular}

\section{Foreigners' influence on the native speakers}

We have seen that the native speakers produce widely varying amounts of FT in conversations with the different foreigners and that the foreigners differ greatly from one another in the extent to which they make various mistakes in speaking Dutch. Is there any correlation between the native speakers' production of FT and the foreigners' rate of making mistakes? We have calculated correlation coefficients to determine whether any such relationship exists. In addition to using the percentage FT utterances in the native speakers' speech, and the combined percentage of mistakes (Error Index) in the foreigners' speech, 'we have calculated a number of utterance length measures for both native speakers and foreigners. Utterance length can be taken as a general reflection of the level of complexity of the utterance and should therefore 
reflect the native speakers' attempts to simplify their utterances and the foreigners' ability to produce complex utterances in Dutch. The length measures used were:

1. Mean length of all utterances in words (MLU).

2. Mean length of all utterances longer than one word (MLU2).

3. Mean length of the 5\% longest utterances produced (MLU5\%).

This measure is less influenced by conversation structure than MLU and better reflects the speaker's competence in a language.

Correlation coefficients were calculated among the various measures (the three length measures and the Error Index) for the foreigners to determine whether they were independent estimates of second-language ability (see Table 4). The three length measures all correlated highly and significantly with one another and somewhat less highly with the Error Index. Only MLU correlated significantly with the Error Index, indicating a rather weak relationship between the ability to produce long utterances and the ability to speak correctly. Similarly, correlation coefficients were calculated for the native speakers' length measures and percentage FT, and high positive correlations among the length measures were found but only low correlations between the length measures and the percentage FT (see Table 5). Interestingly, longer utterances to foreigners tended to be associated with greater use of FT, implying that FT characteristics may have been introduced to simplify complex utterances. These results suggest that, for the foreigners and even more strongly for the native speakers, utterance length is controlled by a different set of factors than the production of mistakes or FT characteristics.

The possible influence of the foreigners' speech on the use of FT or the simplification of the native speakers' speech should be reflected by high correlations between the measures of the foreigners' speech and those of the native speakers' speech. These correlation coefficients are presented in Table 6. It can be seen that the length measures correlate highly and positively, suggesting that foreigners who spoke in relatively long and complex sentences received relatively long sentences back, whereas the foreigners who produced only short and simple Dutch utterances were addressed in relatively short and simple utterances by the native speakers. The use of FT by the native speakers did not, however, correlate significantly with the length of the foreigners' utterances, suggesting that native speakers produced FT in response to other cues than utterance length. A positive and significant correlation was found between the use of FT by the native speakers and the foreigners' Error Index. This means that the foreigners who made many mistakes received many FT utterances, independent of whether they generally produced long or short utterances. The significant correlation between percentage FT and Error Index and the independence of FT production from the foreigners' utterance length is strong evidence in support of the notion that FT is to some extent the re- 
sult of imitation of the foreigners' speech. This conclusion is strengthened by the finding, discussed above, that the most commonly produced FT characteristics were identical to the most commonly produced foreigners' mistakes.

Table 4. Correlations among the length measures and the Error Index of the foreigners' speech

\begin{tabular}{lllll}
\hline & MLU & MLU2 & MLU5\% & Error Index \\
\hline MLU & 1.0 & & & \\
MLU2 & $0.74 * *$ & 1.0 & & \\
MLU5 (percent) & $0.76 * *$ & $0.55^{*}$ & 1.0 & \\
Error Index & $-0.52 *$ & -0.32 & -0.24 & 1.0 \\
$* \mathrm{p}<0.05$ & & & & \\
$* * \mathrm{p}<0.01$ & & & & \\
\hline
\end{tabular}

Table 5. Correlations among the length measures and the percentage FT in the native speakers'speech

\begin{tabular}{lllll}
\hline & MLU & MLU2 & MLU5\% & Percentage FT \\
\hline MLU & 1.0 & & & \\
MLU2 & $0.99 * *$ & 1.0 & & \\
MLU5 (percent) & $0.91^{* *}$ & $0.92^{* *}$ & 1.0 & 1.0 \\
Percentage FT & 0.20 & 0.37 & 0.26 & \\
$* * \mathrm{p}<0.01$ & & & & \\
\hline
\end{tabular}

Table 6. Correlations between the measures of proficiency in the foreigners' speech and the tendency to produce simplified speech and FT characteristics on the part of the native speakers

\begin{tabular}{lllll}
\hline \multirow{2}{*}{ Foreigner measures } & \multicolumn{3}{c}{ Native speaker measures } & \\
\hline MLU & $0.82^{* *}$ & $0.58^{*}$ & $0.70^{* *}$ & 0.02 \\
MLU2 & $0.61^{* *}$ & $0.59^{*}$ & $0.46^{*}$ & 0.29 \\
MLU5(percent) & $0.61^{* *}$ & $0.61^{* *}$ & $0.71^{* *}$ & 0.36 \\
Error Index & -0.17 & -0.15 & 0.09 & $0.45^{*}$ \\
\hline
\end{tabular}




\section{Discussion}

The most important findings of the study are:

1. Foreigner talk characteristics can to some extent be identified with foreigners' mistakes in the second language.

2. In extended conversations between foreigners and native speakers who have frequent contact with foreigners, the native speakers' utterance length is influenced by the utterance length of the foreigner.

3. In extended conversations between foreigners and native speakers who have frequent contact with foreigners, the native speakers' tendency to use foreigner talk correlates significantly with the foreigners' tendency to make certain mistakes.

These findings lend support to the notion that foreigner talk represents an attempt to improve communicative efficiency by mimicking the speech of the foreigner.

It should be pointed out that a number of factors made it very likely that we would find a match between the foreigners' second-language skill and the native speakers' speech characteristics. First, the native speakers studied had considerable experience in carrying on precisely these kinds of conversations with foreigners. It may well be that speakers who have little experience with foreigners would be less successful in achieving the degree of match between the level of their speech and the foreigners' speech attained here. Secondly, the conversations we analyzed were fairly long (mean of 121 utterances). It is clear that the degree of match we found would be impossible to achieve if the native speaker had heard only one or two utterances from the foreigner. In fact, a similar sort of analysis of much shorter conversations carried out on street corners showed no similar relationship. Thirdly, the conversations dealt with fairly abstract and complex topics, which were, however, of sufficient practical importance that the need to achieve successful communication was felt by both participants. Other studies may have found much less use of foreigner talk because the conversations they analyzed were restricted to simpler or more formulaic exchanges (e.g., Where do you come from? How long have you been here? Do you like it here?) or because the native speaker could simply change the topic or leave the situation when communication broke down. Communicative breakdown has been shown to lead to increased simplification and redundancy in adults' speech to children (Bohannon and Marquis, 1977); our results suggest that it also leads to the use of foreigner talk characteristics when addressing second-language speakers. 


\section{References}

Bloomfield, L. (1933). Language. New York: Holt, Rinehart \& Winston.

Bohannon, J. and Marquis, A. (1977). Children's control of adult speech. Child Development 48, 1002-1008.

Campbell, C., Schlue, K. and Vander Brook, S. (1977). Discourse and second language acquisition of yes-no questions. In Proceedings of the Los Angeles Second Language Research Forum, C.A. Henning, (ed.). Los Angeles: U.C.L.A.

Chaudron, C. (1978). English as a medium of instruction in ESL classes: An initial report of a pilot study of the complexity of teachers' speech. Toronto: Ontario Institute for Studies in Education Modern Language Center.

Ferguson, C.A. (1971). Absence of copula and the notion of simplicity: A study of normal speech, baby talk, and pidgins. In Pidginization and creolization of languages, D. Hymes (ed.). London: Cambridge University.

- (1975). Towards a characterization of English Foreigner Talk. Anthropological Linguistics 17, 1-14.

Gaskell, W., Campbell, C. and Vander Brook, S. (1977). Some aspects of foreigner talk. In Proceedings of the Los Angeles Second Language Research Forum, C.A. Henning (ed.). Los Angeles: U.C.L.A.

Hatch, E., Shapira, R. and Gough, J. (1975). 'Foreigner-talk' discourse. Working Papers in English as a Second Language. Los Angeles: U.C.L.A.

Katz, J. (1977). Foreigner talk input in child second language acquisition: Its form and function over time. In Proceedings of the Los Angeles Second Language Research Forum, C.A. Henning (ed.). Los Angeles: U.C.L.A.

Lattey, E. and Müller, B. (1976). Temporary language acquisition: Migrant workers' speech in Germany. In Proceedings of the Fourth International Congress of Applied Linguistics, G. Nickel (ed.). Stuttgart.

Meisel, J. (1975). Ausländerdeutsch und Deutsch ausländischer Arbeiter: Zur möglichen Entstehung eines Pidgins in der BRD. Zeitschrift für Literatur wissenschaft und Linguistik 5(18), 9-53.

- (1977). Ausländerdeutsch und Deutsch ausländischer Arbeiter. In Sprache Ausländischer Arbeiter. Zeitschrift für Linguistik und Literaturwissenschaft $5 ; 18$.

Workgroup on Foreign Workers' Language (1978). Netherlands tegen buitenlanders (Dutch addressed to foreigners), Publication No. 18, Institute for General Linguistics, University of Amsterdam. 